\title{
ANALISIS NILAI PENDIDIKAN DALAM NOVEL SEPATU DAHLAN KARYA KHRISNA PABHICARA
}

\author{
Abdul Aziz \\ STAI Nurul Ilmi Tanjung Balai \\ Jalan Besar Teluk Nibung, Jl. Jend Soeprapto, Muara Sentosa, Sei Tualang Raso, Kota \\ Tanjung Balai, Sumatera Utara 21333 \\ abdaaziz08@gmail.com
}

\begin{abstract}
ABSTRAK
Sastra merupakan ungkapan ekspresi manusia berupa karya tulisan atau lisan berdasarkan pemikiran, pendapat, pengalaman, hingga ke perasaan dalam bentuk yang imajinatif, cerminan kenyataan atau data asli yang dibalut dalam kemasan estetis melalui media bahasa. Dengan demikian karya sastra dapat didekati dengan menggunakan nilai-nilai pendidikan. Masalah penelitian ini tentang nilai pendidikan yang terdapat dalam novel Sepatu Dahlan karya Khrisna Pabhicara. Penelitian ini bertujuan untuk mengetahui gambaran deskripsi nilai pendidikan dalam novel Sepatu Dahlan karya Khrisna Pabhicara yang berjumlah 369 halaman. Penerbit Noura Books, Jakarta. 2012. Data penelitian ini berupa gambaran nilai pendidikan dari segi nilai pendidikan religius, nilai pendidikan moral, nilai pendidikan sosial dan nilai pendidikan budaya. Metode yang digunakan adalah metode deskriptif dengan analisis kualitatif dengan mendeskripsikan gambaran nilai pendidikan dalam novel Sepatu Dahlan karya Khrisna Pabhicara dengan pendekatan nilai pendidikan. Metode ini didasarkan pada pertimbangan kesesuaian antara bentuk penelitian dengan tujuan penelitian. Instrumen penelitian dilakukan dengan studi dokumentasi. Studi dokumentasi dilakukan pada novel Sepatu Dahlan karya Khrisna Pabhicara dengan pendekatan nilai pendidikan. Dari hasil penelitian ini dapat diperoleh informasi nilai pendidikan dari segi nilai pendidikan religius dengan kepolosan, ketekunan, kerajinan dan ketakwaan yang dimilikinya, Dahlan terpilih sebagai pengurus ikatan santri baru yang harus memegang amanat, nilai pendidikan moral lalu Dahlan ingin mengatakan bahwa dia ingin sekolah di SMP Magetan tetapi dia tidak bisa membohongi orang tuanya, nilai pendidikan sosial setelah pulang dari mengikuti tim bola voli Imran dan Arif mengajak Dahlan dan Kadir bermain ke sumur tua dan nilai pendidikan budaya Ojo Wedi Melarat Yang Penting Tetap Jujur artinya kita boleh miskin harta tetapi kita boleh miskin hati.
\end{abstract}

Kata kunci: Analisis, Pendekatan, dan Nilai Pendidikan

\begin{abstract}
Literature is an expression of human expression in the form of written or oral works based on thoughts, opinions, experiences, to feelings in imaginative forms, reflections of reality or original data wrapped in aesthetic packaging through language media. Thus, literary works can be approached using educational values. The problem of this research is about the value of education contained in the novel Shoes Dahlan by Khrisna Pabhicara. This study aims to describe the description of the value of education in the novel Shoes Dahlan by Khrisna Pabhicara which amounts to 369 pages. Noura Books Publisher, Jakarta. 2012. The data of this study is a description of the value of education in terms of the value of religious education, the value of moral education, the value of social education and the value of cultural education. The method used is descriptive method with qualitative analysis by describing the description of the value of education in the novel Shoes Dahlan by Khrisna Pabhicara with an educational value approach. This method is based on consideration of the suitability of the research form with the research objectives. The research instrument was carried out with a documentation study. Documentation study was conducted on the novel Shoes Dahlan by Khrisna Pabhicara with an educational value approach. From the results of this study, it can be obtained information on the value of education in terms of the value of religious education with his innocence, perseverance, craft and piety, Dahlan was chosen as the administrator of the new santri association who must hold the mandate, the value of moral education then Dahlan wanted to say that he wanted to go to junior high school Magetan but he can't lie to his parents, the value of social education after coming home
\end{abstract}


from joining the volleyball team Imran and Arif invite Dahlan and Kadir to play to an old well and the value of Ojo Wedi's cultural education is poor. heart.

Keywords: Analysis, Approach, and Educational Value

\section{PENDAHULUAN}

Sastra dianggap semakin penting karena sastra diciptakan namun terus diapresiasikan masyarakat untuk memperhalus budi dan memperkaya spiritual serta hiburan dan juga telah masuk dalam kurikulum sekolah sebagai pengetahuan budaya. Penguasaan teori merupakan salah satu cara dalam memahami karya sastra, dapat dipertanggungjawabkan secara ilmiah, meskipun sastra itu sendiri bersifat penafsiran. Untuk itu mahasiswa jurusan bahasa dan sastra Indonesia yang notabenenya bergelut di dunia sastra perlu memahami dan menguasai ilmu sastra, dan melalui kegiatan-kegiatan yang lainnya menyangkut tentang sastra.

Sastra sebagai hasil kehidupan mengandung nilai-nilai sosial, filosofi, religi dan sebagainya. Baik yang bertolak dari pengungkapan kembali maupun yang merupakan menciptakan terbaru semuanya dirumuskan secara tersurat dan tersirat. Sastra tidak saja lahir karena kejadian, tetapi juga dari kesadaran penciptaannya bahwa sastra sebagai sesuatu yang imajinatif, fiktif, dll, juga harus melayani misi-misi yang dapat dipertanggungjawabkan serta bertendens. Sastrawan pada waktu menciptakan karyanya tidak saja didorong oleh hasrat untuk menciptakan keindahan, tetapi juga berkehendak untuk menyampaikan pikiran-pikirannya, pendapat-pendapatnya, dan kesan-kesan perasaannya terhadap sesuatu.

Karya sastra, sebagai sebuah struktur terdiri atas unsur yang tersusun secara bersistem. Membicarakan sastra yang bersifat imajinatif, berhadapan dengan tiga jenis genre sastra, yaitu prosa, puisi dan drama. Prosa dalam pengertian kesastraan juga disebut fiksi, teks naratif, atau wacana naratif. Istilah fiksi dalam pengertian ini adalah cerita rekaan atau cerita khayalan. Hal itu disebabkan karena fiksi merupakan karya naratif yang isinya tidak menyaran pada kebenaran sejarah sebagai sebuah karya imajiner, fiksi menawarkan berbagai permasalahan manusia dan kemanusiaan, hidup dan kehidupan. Salah satu jenis prosa adalah novel, merupakan bagian dari karya fiksi yang memuat pengalaman manusia secara menyeluruh atau merupakan suatu terjemahan tentang perjalanan hidup yang bersentuhan dengan kehidupan manusia, sehingga dapat dikatakan bahwa karya fiksi berupa novel adalah suatu potret realitas yang terwujud melalui bahasa yang estetis.

Penelitian yang menggunakan pendekatan nilai pendidikan terhadap karya sastra merupakan bentuk kreativitas terhadap hubungan kehidupannya. Dalam karya sastra akan tersimpan nilai atau pesan yang berisi amanat atau nasihat. Melalui karyanya, pencipta karya sastra berusaha untuk mempengaruhi pola piker pembaca dan ikut mengkaji tentang baik dan buruk, benar mengambil pelajaran, teladan yang patut ditiru sebaliknya, untuk dicela bagi yang tidak baik.

Identifikasi dalam penelitian ini adalah uraian faktor yang mendorong peneliti untuk mengadakan penelitian mengenai analisis nilai pendidikan novel Sepatu Dahlan karya Khrisna Pabhicara. Kejelasan identifikasi masalah sangat diperlukan sebagai pedoman bagi peneliti untuk kemudahan proses pengujian, menghindari kemungkinankemungkinanterjadinya penyimpangan dalam pembahasan masalah. 
Mengingat keterbatasan dari kemampuan yang peneliti miliki, untuk menghindari kesimpang siuran dalam pembahasan dan penganalisisan maka penelitian dibatasi pada analisis gambaran nilai pendidikan dalam novel Sepatu Dahlan karya Khrisna Pabhicara. Permasalahan sebagai dasar penulisan, maka berdasarkan identifikasi dan pembatasan masalah di dalam penelitian ini adalah bagaimana deskripsi nilai pendidikan dalam novel Sepatu Dahlan karya Khrisna Pabhicara.

Setiap penelitian harus memiliki tujuan yang jelas karena dengan tujuan yang jelas akan memudahkan peneliti atau pembaca untuk meneliti permasalahan. Berdasarkan rumusan masalah yang dikemukakan di atas, maka secara umum tujuan penelitian ini adalah untuk mendeskripsikan nilai pendidikan dalam novel Sepatu Dahlan karya Khrisna Pabhicara. Penelitian ini bermanfaat secara teoretis maupun praktis, penelitian ini merupakan masukan kepada novel agar dalam penulisan novel lebih mengarah kepada kehidupan sosial yang terjadi saat ini. Secara praktis, penelitian ini bermanfaat yang diharapkan dari penelitian ini. Sebagai bahan masukan dan pengetahuan bagi guru bidang studi Bahasa dan Sastra Indonesia, khususnya dalam pengkajian sastra.

Nilai pendidikan religius merupakan suatu kesadaran yang menggejala secara mendalam dalam lubuk hati manusia sebagai human nature. Religi tidak hanya menyangkut segi kehidupan secara lahiriah melainkan juga menyangkut keseluruhan diri pribadi manusia secara total dalam integrasinya hubungan ke dalam keesaan Tuhan (Rosyadi, 1995: 90). Nilai-nilai religious bertujuan untuk mendidik agar manusia lebih baik menurut tuntunan agama dan selalu ingat kepada Tuhan. Nilai-nilai religius yang terkandung dalam karya sastra dimaksudkan agar penikmat karya tersebut mendapatkan renungan-renungan batin dalam kehidupan yang bersumber pada nilai-nilai agama. Nilainilai religius dalam sastra bersifat individual dan personal.

Nilai pendidikan moral merupakan sesuatu yang igin disampaikan pengarang kepada pembaca, merupakan makna yang terkandung dalam karya sastra, makna yang disaratkan lewat cerita. Moral dapat dipandang sebagai tema dalam bentuk yang sederhana, tetapi tidak semua tema merupaka moral (Kenny dalam Nurgiyantoro, 2005: 320). Moral merupakan pandangan pengarang tentang nilai-nilai kebenaran dan pandangan itu yang ingin disampaikan kepada pembaca. Hasbullah (2005: 194) menyatakan bahwa, moral merupakan kemampuan seseorang membedakan antara yang baik dan yang buruk.

Nilai pendidikan sosial mengacu pada hubungan individu dengan individu yang lain dalam sebuah masyarakat. Bagaimana seseorang harus bersikap, bagaimana cara mereka menyelesaikan masalah, dan menghadapi situasi tertentu juga termasuk dalam nilai sosial. Dalam masyarakat Indonesia yang sangat beraneka ragam coraknya, pengendalian diri adalah sesuatu yang sangat penting untuk menjaga keseimbangan masyarakat. Nilai-nilai pendidikan budaya menurut Rosyadi (1995:74) merupakan sesuatu yang dianggap baik dan berharga oleh suatu kelompok masyarakat atau suku bangsa yang belum tentu dipandang baik pula oleh kelompok masyarakat atau suku bangsa lain sebab nolai budaya membatasi dan memberikan karakteristik pada sutu masyarakat dan kebudayaannya. 


\section{METODE}

Penelitian ini merupakan studi pustaka dan kegiatan yang dilakukakn dengan mengumpulkan dan menganalisis data penelitian dari Novel Sepatu Dahlan karya Khrisna Pabhicara. Waktu yang dilaksanakan dalam melakukan penelitian ini selama enam bulan yaitu terhitung dari bulan Oktober 2020 sampai dengan bulan Maret 2021. Sumber data penelitian ini adalah tampilan yang berupa fakta- fakta lisan atau tulisan yang dicermati oleh peneliti dan benda-benda yang diamati sampai detalinya agar dapat tertangkap makna yang tersirat dalam dokumen bendanya. Menurut Moleong (dalam Arikunto, 2010;22). Sumber data dari penelitian adalah novel Sepatu Dahlan karya Khrisna Pabhicara yang berjumlah 369 halaman. Penerbit Noura Books, Jakarta. 2012. Adapun data penelitian ini adalah gambaran nilai pendidikan, dalam Novel Sepatu Dahlan karya Khrisna Pabhicara, jumlah halaman (369 Halaman), Penerbit (Noura Books, Jakarta), tahun terbit (2012), cetakan (1).

Metode penelitian adalah cara untuk mengungkapkan atau menganalisis suatu permasalahan yang menjadi objek penelitian. Untuk mencapai tujuan yang telah ditetapkan, penulis memerlukan metode. Metode merupakan cara kerja yang harus ditempuh dalam suatu penelitian ilmiah. Metode yang digunakan dalam penelitian ini adalah melalui metode deskripstif dengan analisis data kualitatif model kajian tekstual dengan pendekatan nilai pendidikan. Penelitian deskriptif kualitatif adalah penelitian yang ditujukan untuk mendeskripsikan dan menganalisis objek-objek, peristiwa, aktivitas sosial secara alamiah (Moleong, 2010:11). Penelitian ini berupaya memaparkan suatu peristiwa secara rinci, sistematis, cermat, dan faktual mengenai aspek perkembangan nilai pendidikan, dalam novel Sepatu Dahlan karya Khrisna Pabhicara. Instrumen penelitian dilakukan dengan studi dokumentasi. Studi dokumentasi dilakukan dengan menganalisis nilai pendidikan novel Sepatu Dahlan karya Khrisna Pabhicara. Penelitian ini dilakukan peninjauan dengan mencatat, memberi tanda pada bagian-bagian baik berupa nilai pendidikan maupun uraian peneliti yang dapat dianggap bermanfaat dan berpengaruh bagi pembaca. Instrumen dalam penelitian yaitu adalah (1) mencari dan menentukan nilai pendidikan yang dikaji,(2) menelusuri perkembangan nilai pendidikan yang dikaji,(3) mengidentifikasi macam-macam nilai-nilai pendidikan dalam mendeskripsikan,serta mengklasifikasikasinnya.

Analisis data merupakan bagian bagian yang amat penting dalam metode ilmiah, karena dengan analisislah data tersebut data diberi arti dan makna yang berguna dalam memecahkan masalah penelitian. Teknik yang digunakan dalam penelitian ini adalah menentukan data. Jadi langkah-langkah yang ditempuh oleh si penulis dalam penelitian. Membaca sastra secara cermat novel Sepatu Dahlan karya Khrisna Pabhicara Peneliti membaca novel yang menjadi objek penelitian, dalam hal ini adalah novel Sepatu Dahlan karya Khrisna Pabhicara. Kegiatan membaca novel dilakukan dengan teknik membaca sekilas dilakukan untuk memahami jalan cerita, pada tahap membaca pemahaman yang bertujuan agar peneliti memahami permasalahan yang terdapat pada novel yang dikaji. Memahami gambaran nilai pendidikan dalam novel Sepatu Dahlan karya Khrisna Pabhicara. Membaca evaluasi tujuannya untuk menyimpulkan novel Sepatu Dahlan karya Khrisna Pabhicara. Permasalahan yang terdapat dalam pada novel Sepatu Dahlan karya Khrisna Pabhicara. Mengumpulkan data yang berkaitan dengan penelitian. 


\section{HASIL DAN PEMBAHASAN}

Dalam penelitian ini peneliti terlebih dahulu membaca secara terperinci Sepatu Dahlan karya Khrisna Pabhicara, hal ini dilakukan agar peneliti memperoleh pemahaman nilai pendidikan dalam novel Sepatu Dahlan karya Khrisna Pabhicara dengan pendekatan nilai pendidikan. Ditemukan hasil penelitian dilihat dari nilai pendidikan religius, nilai pendidikan moral, nilai pendidikan sosial dan nilai pendidikan budaya.

1. Dengan kepolosan, ketekunan, kerajinan dan ketakwaan yang dimilikinya, Dahlan terpilih sebagai pengurus ikatan santri yang baru, yang harus memegang amanat yang dibebankan olehnya. (Nilai pendidikan religius)

2. Lalu Dahlan ingin mengatakan bahwa dia ingin sekolah di SMP Magetan tetapi dia tidak bias membohongi orangtuanya. (Nilai pendidikan moral)

3. Setelah pulang dari mengikuti tim bola voli Imran dan Arif mengajak Dahlan dan Kadir bermain ke sumur tua yaitu Suco dan Cigrok yang membuat sahabtnya Kadir gelisah ketika diajak bermain ke sumur tua tersebut terutama sumur cigrok. (Nilai pendidikan social)

4. Ojo wedi melarat yang penting tetap jujur dan kita boleh miskin harta tetapi kita tidak boleh miskin hati, kata-kata yang membuat Dahlan merasa bersalah dan menangis dengan kata-kata yang diucapkan oleh kakaknya. (Nilai pendidikan budaya).

Karya sastra dapat didekati dengan menggunakan pendekatan nilai-nilai pendidikan yang mempelajari bentuk nilai-nilai moral, usaha untuk memahami bagaimana menyesuaikan diri dengan lingkungannya dan juga membatasi kebutuhannya. Adapun hal yang di analisa ialah membahas tentang gambaran nilai pendidikan, dalam novel Sepatu Dahlan karya Khrisna Pabhicara. Analisis nilai-nilai pendidikan merupakan masalah yang dibahas oleh peneliti.

\section{SIMPULAN}

Berdasarkan hasil penelitian yang telah dijelaskan dapat ditarik suatu kesimpulan. Hal ini dimaksudkan agar pendapat-pendapat yang telah dikemukakan dalam pembahasan dapat menjadi suatu pendapat yang bersifat umum dan universal. Aspek nilai pendidikan yang ada pada novel Sepatu Dahlan karya Khrisna Pabhicara ini adalah (1) nilai pendidikan (2) religius, (3) nilai pendidikan moral, (4) nilai pendidikan sosial dan (5) nilai pendidikan budaya. 


\section{DAFTAR PUSTAKA}

Arikunto, S. 2010. Prosedur Penelitian Suatu Pendekatan Praktik. Jakarta: Rineka cipta.

Hasbullah. 2005. Dasar-Dasar Ilmu Pendidikan. Jakarta: Raja grafindo Persada.

Khair, U., \& Misnawati, M. (2022). Indonesian language teaching in elementary school: Cooperative learning model explicit type instructions chronological technique of events on narrative writing skills from interview texts. Linguistics and Culture Review, 6, 172-184.

Khrisna Pabichara.2012. Sepatu Dahlan. Noura Books, Jakarta.

Moleong, Lexy J. 1988. Metodologi Penelitian Kualitatif. Bandung: PT Remaja Rosdakarya.

Misnawati, M. P., \& Anwarsani, S. P. (2000). Teori Stuktural Levi-Strauss dan Interpretatif Simbolik untuk Penelitian Sastra Lisan. GUEPEDIA.

Nurachmana, A., Purwaka, A., Supardi, S., \& Yuliani, Y. (2020). Analisis Nilai Edukatif dalam Novel Orang-orang Biasa Karya Andrea Hirata: Tinjauan Sosiologi Sastra. ENGGANG: Jurnal Pendidikan, Bahasa, Sastra, Seni, dan Budaya, 1(1), 57-66.

Nurgiyantoro, B. 2005. Sastra Anak. Yogyakarta: UGM Press

Rosyadi.1995. Nilai-nilai Budaya dalam Naskah Kaba. Jakarta: CV Dewi Sari

Semi, A. 1993. Anatomi Sastra. Bandung: Angkasa Raya.

Setiani, F., \& Arifin, Z. (2021). Nilai Edukatif Tokoh Burlian Dalam Novel Si Anak Spesial Karya Tere Liye: Tinjauan Sosiologi Sastra Sebagai Bahan Ajar Cerita Inspiratif. ENGGANG: Jurnal Pendidikan, Bahasa, Sastra, Seni, dan Budaya, 2(1), $1-12$.

Siswanto, W. 2013. Pengantar Teori Sastra. Jakarta: PT Grasindo.

Perdana, I., \& Misnawati, M. P. (2019). Cinta dan Bangga Berbahasa Indonesia Di Perguruan Tinggi. SPASI MEDIA. 